\title{
A Comment on Application of Hand Towel Drape over Dingman Mouth Gag
}

\section{Kun Hwang}

Department of Plastic Surgery, Inha University School of Medicine, Incheon, Korea

\section{To the Editor:}

I have read with great interest the article entitled, "Application of Hand Towel Drape over Dingman Mouth Gag," by Choi and Park (Arch Craniofac Surg 2015;16:29-30) [1] and wish to share a comment. In the paper, the authors describe the usage of a towel drape over the mouth gag site. In Figs. 1 and 2, the towel covers the two lateral cheek retractors, tongue blades, and most of the upper and lower springs.

While the authors state that this towel prevents suture material from being caught in the gag, I am afraid this precisely defeats the very purpose of the spring coils, whose design it is to hold sutures in place until they are ready to be tied. The idea of suture-indexing spring coils was first adopted to mouth gag by Professor Kilner at Oxford prior to World War II. I would leave this comment with the quotation of someone who personally knew both Drs. Kilner and Dingman-Dr. Millard Jr.
He wrote "One of the most disciplined aspect of the Kilner's surgery was his suturing. He would place an entire row of sutures for one layer and hang them in an orderly array on the spring coil on his gag. Then he would tie them all and cut the ends before placing the next entire row of stitches" $[2,3]$.

From this reason, it would be wise think twice before using this "Peeping Tom like Hole."

\section{REFERENCES}

1. Choi KB, Park MC. Application of hand towel drape over Dingman mouth gag. Arch Craniofac Surg 2015;16:29-30.

2. Millard DR Jr. Cleft craft: the evolution of its surgery. III. Alveolar and palatal deformities. Boston; Little Brown; 1980.

3. Kilner TP. Cleft lip and palate repair technique. St Thomas Hosp Rep. 1937;2:127-40.

\section{Correspondence: Kun Hwang}

Department of Plastic Surgery, Inha University School of Medicine, 27 Inhang-ro, Jung-gu, Incheon 22332, Korea

E-mail: jokerhg@inha.ac.kr

No potential conflict of interest relevant to this article was reported.

Received May 4, 2015 / Revised June 25, 2015 / Accepted July 15, 2015 


\section{Reply, Myong Chul Park:}

Thank you for the insightful comment and for the invaluable opportunity to review history of oral surgery instrumentation.

Aside from Sir Harold Gillies, Professor Thomas Pomfret Kilner was the only plastic surgeon in England at the beginning of the specialty. He had a special interest in the problem of cleft palate and was an early pioneer in the V-Y advancement of palatal flaps. His discipline as an operator and academic was noted by many-of which the most famous account can be found in Dr. Milliard's book. While the mouth gag itself was not an original invention, Kilner added the spring coil to the preexisting C-frame mouth gags [1].

Dr. Reed Dingman was a Barnes trainee in general and plastic surgery in the middle of 20th century and began the plastic surgery program at the University of Michigan [2]. The mouth gag that bores his name was actually developed between Dr. William Grabb and himself, and was a significant departure from the open
C-framed mouth gag designs. The spring coil was retained to "provide a convenient place to secure traction sutures or uncut sutures." [3]

At our institution, we have been using the spring coil for the tagging of the oral flap to allow exposure and further dissection. As we have stated in the paper, the towel drape was used only when the dissection and mobilization of the oral and nasal flaps have been completed, at which point the each suture was tied prior to the next stitch.

\section{REFERENCES}

1. Ameer F, Singh A, Kumar S. The story of mouth gags. J Cleft Lip Palate Craniofacial Anomalies 2014;1:70-7.

2. Harijan A, Halvorson EG. Eponymous instruments in plastic surgery. Plast Reconstr Surg 2011;127:456-65.

3. Dingman RO, Grabb WC. A new mouth gag. Plast Reconstr Surg Transplant Bull 1962;29:208-9.

http://dx.doi.org/10.7181/acfs.2015.16.2.103

Correspondence: Myong Chul Park

Department of Plastic and Reconstructive Surgery, Ajou University School of Medicine, 164 World cup-ro, Yeongtong-gu, Suwon 16499, Korea

E-mail:mpark@ajou.ac.kr

No potential conflict of interest relevant to this article was reported.

Received May 18, 2015 / Revised July 9, 2015 / Accepted July 30, 2015 